Author affiliations appear at the end of this article.

Published online ahead of print at www.jco.org on June 20, 2016.

Support information appears at the end of this article.

N.W. and E. M.P. contributed equally to this work.

Authors' disclosures of potential conflicts of interest are found in the article online at www.jco.org. Author contributions are found at the end of this article.

Corresponding author: Nicolas Wentzensen, MD, PhD, MS, Division of Cancer Epidemiology and Genetics,

National Cancer Institute, Room 7-E114, 9609 Medical Center Dr, Bethesda, MD 20892-9774; e-mail: wentzenn@mail.nih. gov.

(c) 2016 by American Society of Clinical Oncology

0732-183X/16/3424w-2888w/\$20.00

DOI: 10.1200/JCO.2016.66.8178

\title{
Ovarian Cancer Risk Factors by Histologic Subtype: An Analysis From the Ovarian Cancer Cohort Consortium
}

Nicolas Wentzensen, Elizabeth M. Poole, Britton Trabert, Emily White, Alan A. Arslan, Alpa V. Patel, V. Wendy Setiawan, Kala Visvanathan, Elisabete Weiderpass, Hans-Olov Adami, Amanda Black, Leslie Bernstein, Louise A. Brinton, Julie Buring, Lesley M. Butler, Saioa Chamosa, Tess V. Clendenen, Laure Dossus, Renee Fortner, Susan M. Gapstur, Mia M. Gaudet, Inger T. Gram, Patricia Hartge, Judith Hoffman-Bolton, Annika Idahl, Michael Jones, Rudolf Kaaks, Victoria Kirsh, Woon-Puay Koh, James V. Lacey Jr, I-Min Lee, Eva Lundin, Melissa A. Merritt, N. Charlotte Onland-Moret, Ulrike Peters, Jenny N. Poynter, Sabina Rinaldi, Kim Robien, Thomas Rohan, Dale P. Sandler, Catherine Schairer, Leo J. Schouten, Louise K. Sjöholm, Sabina Sieri, Anthony Swerdlow, Anna Tjonneland, Ruth Travis, Antonia Trichopoulou, Piet A. van den Brandt, Lynne Wilkens, Alicja Wolk, Hannah P. Yang, Anne Zeleniuch-Jacquotte, and Shelley S. Tworoger

\section{$\begin{array}{llllllll}\text { A } & \text { B } & \text { S } & \text { T } & \text { R } & \text { A } & \text { C } & \text { T }\end{array}$}

\section{Purpose}

An understanding of the etiologic heterogeneity of ovarian cancer is important for improving prevention, early detection, and therapeutic approaches. We evaluated 14 hormonal, reproductive, and lifestyle factors by histologic subtype in the Ovarian Cancer Cohort Consortium (OC3).

\section{Patients and Methods}

Among 1.3 million women from 21 studies, 5,584 invasive epithelial ovarian cancers were identified (3,378 serous, 606 endometrioid, 331 mucinous, 269 clear cell, 1,000 other). By using competingrisks Cox proportional hazards regression stratified by study and birth year and adjusted for age, parity, and oral contraceptive use, we assessed associations for all invasive cancers by histology. Heterogeneity was evaluated by likelihood ratio test.

\section{Results}

Most risk factors exhibited significant heterogeneity by histology. Higher parity was most strongly associated with endometrioid (relative risk [RR] per birth, $0.78 ; 95 \% \mathrm{Cl}, 0.74$ to 0.83 ) and clear cell (RR, 0.68; 95\% Cl, 0.61 to 0.76$)$ carcinomas ( $P$ value for heterogeneity $[P$-het $]<.001)$. Similarly, age at menopause, endometriosis, and tubal ligation were only associated with endometrioid and clear cell tumors $(P$-het $\leq .01)$. Family history of breast cancer $(P$-het $=.008$ ) had modest heterogeneity. Smoking was associated with an increased risk of mucinous (RR per 20 pack-years, 1.26; 95\% $\mathrm{Cl}$, 1.08 to 1.46 ) but a decreased risk of clear cell $(\mathrm{RR}, 0.72 ; 95 \% \mathrm{Cl}, 0.55$ to 0.94$)$ tumors ( $P$-het $=.004)$. Unsupervised clustering by risk factors separated endometrioid, clear cell, and low-grade serous carcinomas from high-grade serous and mucinous carcinomas.

\section{Conclusion}

The heterogeneous associations of risk factors with ovarian cancer subtypes emphasize the importance of conducting etiologic studies by ovarian cancer subtypes. Most established risk factors were more strongly associated with nonserous carcinomas, which demonstrate challenges for risk prediction of serous cancers, the most fatal subtype.

\section{J Clin Oncol 34:2888-2898. (C) 2016 by American Society of Clinical Oncology}

\section{INTRODUCTION}

Ovarian cancer is the most lethal gynecologic cancer, with $>152,000$ deaths worldwide each year. ${ }^{1}$ Most ovarian cancers are detected at a late stage and have a poor prognosis. Screening for ovarian cancer did not reduce mortality in two large screening trials. ${ }^{2,3}$ An understanding of the etiologic heterogeneity of ovarian cancer is critical for development of new prevention strategies.

Although multiple carcinogenic mechanisms for ovarian tumorigenesis have been hypothesized, including incessant ovulation, hormonal stimulation, and chronic inflammation, ${ }^{4-7}$ the etiology of ovarian cancer is not well understood partly due to its heterogeneous nature. Disease 
subtypes have been categorized by putative precursor lesions, mutations, and histology. ${ }^{8,9}$ Low-grade serous, mucinous, clear cell, and endometrioid tumors are believed to arise from inclusion cysts or implants in the ovarian surface epithelium and have KRAS, BRAF, or PTEN mutations. High-grade serous tumors, characterized by TP53 mutations, are believed to arise in the fallopian tube or ovarian epithelium, are more aggressive, and have poorer outcomes than other types. ${ }^{8-10}$ Due to limited power, individual epidemiologic and biomarker studies usually have considered risk factor associations for all ovarian tumors together. Individual cohorts and individual-level meta-analyses of primarily case-control studies have reported differential associations by subtype for menopausal hormone therapy (HT) use, oral contraceptive (OC) use, parity, smoking, and body mass index (BMI). ${ }^{1-17}$ To establish etiologic models that account for ovarian cancer heterogeneity, a unified prospective evaluation of multiple ovarian cancer risk factors needs to account for heterogeneity. In the Ovarian Cancer Cohort Consortium (OC3), we evaluated associations of 14 key risk factors with invasive epithelial ovarian cancer risk overall and by histologic subtype based on pooled individual-level data from 5,584 invasive ovarian cancer cases from a combined cohort of $>1.3$ million women enrolled in 21 prospective studies.

\section{PATIENTS AND METHODS}

\section{Study Population}

The analysis included women participating in 21 prospective cohort studies from North America, Asia, and Europe (Table 1). Prospective follow-up of ovarian cancer end points through questionnaires, medical records, or cancer registries as well as follow-up for death were required for participation. Minimal required information included age at study entry, OC use, and parity. All studies obtained institutional approval for cohort maintenance as well as participation in the OC3. The OC3 data coordinating center and analytic approaches were approved by the institutional review board of the Brigham and Women's Hospital (Boston, MA).

\section{Exposure Definitions}

Full baseline cohort data (19 studies) or case-cohort data sets with weights for subcohort members (two studies) were harmonized centrally. Exposures included parity (ever versus never; number of births: per one birth and one, two, three, four or more births), OC use (ever versus never; duration of use: per 5 years of use and never, $\leq 1,>1$ to $5,>5$ to $10,>10$ years), duration of breastfeeding (per 1 year among parous women), age at menarche (per 1 year and $\leq 11,12,13,14, \geq 15$ years), age at natural menopause (postmenopausal women only: per 5 years and $\leq 40,>40$ to $45,>45$ to $50,>50$ to $55,>55$ years), menopausal HT use (ever versus never; duration of use: per 1 year and never, $\leq 5$,

\begin{tabular}{|c|c|c|c|c|c|c|c|c|}
\hline Study Name & $\begin{array}{l}\text { Study } \\
\text { Acronym }\end{array}$ & Location & $\begin{array}{c}\text { Baseline } \\
\text { Enrollment } \\
\text { Period }\end{array}$ & $\begin{array}{l}\text { Baseline } \\
\text { Cohort } \\
\text { Size* }\end{array}$ & $\begin{array}{c}\text { Median Study } \\
\text { Participant Age } \\
\text { (years) }\end{array}$ & $\begin{array}{l}\text { Median } \\
\text { Follow-Up } \\
\text { (years) }\end{array}$ & $\begin{array}{l}\text { Last Year } \\
\quad \text { of } \\
\text { Follow-Up }\end{array}$ & $\begin{array}{c}\text { Invasive } \\
\text { Ovarian } \\
\text { Cancer Cases }\end{array}$ \\
\hline NIH-AARP Diet and Health Study & AARP & US & 1995-1997 & 153,069 & 62 & 11 & 2006 & 703 \\
\hline $\begin{array}{l}\text { Breast Cancer Detection Demonstration } \\
\text { Project Follow-Up Study }\end{array}$ & BCDDP & US & 1987-1989 & 36,212 & 61 & 9 & 1999 & 159 \\
\hline Breakthrough Generations Study & BGS & UK & $2001-2014$ & 101,869 & 48 & 6 & 2014 & 75 \\
\hline Canadian Study of Diet, Lifestyle, and Health & CSDLH & Canada & 1991-1999 & $2,745 \dagger$ & 58 & 16 & 2010 & 90 \\
\hline Campaign Against Cancer and Stroke & CLUEII & US & 1989 & 12,382 & 46 & 22 & 2012 & 82 \\
\hline Cancer Prevention Study II Nutrition Cohort & CPSII-NC & US & 1992-1993 & 65,884 & 62 & 15 & 2009 & 533 \\
\hline California Teachers Study & CTS & US & 1995-1999 & 43,778 & 50 & 15 & 2010 & 185 \\
\hline $\begin{array}{l}\text { European Prospective Investigation Into } \\
\text { Cancer and Nutrition Study }\end{array}$ & EPIC & Europe & $1992-2000$ & 263,796 & 51 & 13 & 2010 & 671 \\
\hline lowa Women's Health Study & IWHS & US & 1986 & 30,537 & 61 & 23 & 2010 & 263 \\
\hline Multiethnic/Minority Cohort Study $\ddagger$ & MEC & US & 1993-1998 & 16,474 & 57 & 11 & 2011 & 75 \\
\hline Nurses' Health Study $1980 \S$ & NHS80 & US & 1980-1982 & 86,608 & 46 & 16 & 1998 & 351 \\
\hline Nurses' Health Study 1996§ & NHS96 & US & 1996-1998 & 67,530 & 62 & 14 & 2010 & 417 \\
\hline Nurses' Health Study II & NHSII & US & 1989-1990 & 111,800 & 35 & 20 & 2011 & 215 \\
\hline New York University Women's Health Study & NYU & US & 1984-1991 & 12,427 & 49 & 24 & 2012 & 129 \\
\hline Netherlands Cohort Study on Diet and Cancer & NLCS & Netherlands & 1986 & $2,757 \dagger$ & 62 & 17 & 2003 & 448 \\
\hline $\begin{array}{l}\text { Prostate, Lung, Colorectal and Ovarian } \\
\text { Cancer Screening Trial }\end{array}$ & PLCO & US & 1993-2002 & 60,191 & 62 & 12 & 2009 & 358 \\
\hline Singapore Chinese Health Study & $\mathrm{SCHS}$ & Singapore & 1993-1999 & 31,939 & 56 & 14 & 2011 & 95 \\
\hline Sister Study & SS & US & 2003-2009 & 39,195 & 55 & 5 & 2012 & 39 \\
\hline Swedish Mammography Cohort Study & SMC & Sweden & 1997 & 34,427 & 60 & 14 & 2011 & 161 \\
\hline Vitamins and Lifestyle Cohort & VITAL & US & $2000-2002$ & 28,331 & 60 & 10 & 2011 & 130 \\
\hline Women's Lifestyle and Health Study & WLHS & Sweden & 1991-1992 & 49,087 & 40 & 21 & 2012 & 201 \\
\hline Women's Health Study & WHS & US & 1993-1996 & 33,548 & 53 & 18 & 2012 & 204 \\
\hline \multicolumn{9}{|c|}{$\begin{array}{l}\text { Abbreviation: NIH, National Institutes of Health. } \\
\text { *After exclusions for baseline cancers and women with bilateral oophorectomy. } \\
\text { †These cohorts were included as a case-cohort design, which reflected a total cohort population of 39,618 women for the CSDLH and 62,573 women for the NLCS. } \\
\text { Appropriate weights for subcohort selection were applied in all analyses. } \\
\text { łIncluded only white women. } \\
\text { §The Nurses' Health Study was broken into two study periods ( } 1980 \text { to June } 1996 \text { and July } 1996 \text { to } 2010 \text { ) because the follow-up was nearly twice as long as any other } \\
\text { study. We updated the exposures in } 1996 \text { for that follow-up period. }\end{array}$} \\
\hline
\end{tabular}


$>5$ years), tubal ligation (ever versus never), hysterectomy (ever versus never), endometriosis (ever versus never), first-degree family history of breast cancer (ever versus never), first-degree family history of ovarian cancer (ever versus never), BMI (per $5 \mathrm{~kg} / \mathrm{m}^{2}$ and $<20,20$ to $<25,25$ to $<30,30$ to $<35, \geq 35 \mathrm{~kg} / \mathrm{m}^{2}$ ), height (per $0.05 \mathrm{~m}$ and $<1.60,1.60$ to $<1.65,1.65$ to $1.70, \geq 1.70 \mathrm{~m}$ ), and smoking (ever versus never; per 20 pack-years and $\leq 10,>10$ to $20,>20$ to $35,>35$ pack-years). Studies that did not collect information on a specific risk factor were excluded from the analysis of that factor (Appendix Table A1, online only), which led to different samples sizes for each variable (Appendix Table A2, online only).

\section{Outcome Definitions}

Epithelial ovarian or peritoneal cancer cases were confirmed through cancer registries or medical record review (International Classification of Diseases [9th revision codes 183 and 158 and 10th revision code C56]). Ascertainment of incident cancers was $\geq 90 \%$ for all studies and $\geq 95 \%$ for 17 studies. We evaluated associations of risk factors with all invasive epithelial cancers combined $(n=5,584)$. Next, we evaluated associations with the four most common histologic types of invasive epithelial ovarian cancers $(n=4,584)$ : serous/poorly differentiated, endometrioid, mucinous, and clear cell. One thousand cases had another histology or were missing histology information. Serous tumors were further divided by grade (well-, moderately, or poorly differentiated or unknown).

\section{Statistical Methods}

Women with a history of cancer (other than nonmelanoma skin cancer), with bilateral oophorectomy before study entry, or with missing age at baseline were excluded. We calculated hazard ratios (HRs) and 95\% CIs by using competing-risks Cox proportional hazards regression to evaluate associations between exposures and ovarian cancer end points. ${ }^{18}$ Follow-up time was time between study entry and date of ovarian cancer diagnosis, death, or end of follow-up, whichever occurred first. Survivor function plots for exposures showed parallel curves, which suggest no relevant deviation from proportional hazards. In primary analyses, we pooled data from all cohorts and stratified by year of birth and cohort to account for potential differences in baseline hazards by these factors. Statistical heterogeneity of associations across subtypes was assessed through a likelihood ratio test that compared a model that allowed for the association for the risk factor of interest to vary by histology versus one that did not allow for the association to vary. ${ }^{16}$ We also used random-effects meta-analysis to combine cohort-specific estimates and to assess betweenstudy heterogeneity. All models were adjusted for age at entry, number of children, and duration of OC use, unless the exposure of interest was collinear with one of these factors. Hysterectomy analyses were also adjusted for HT use. For missing data in covariates, we included a missing indicator in the model. The Sister Study was excluded from analyses of family history because all participants had a family history of breast or ovarian cancer. To evaluate whether our primary models sufficiently accounted for confounding, we performed a model that adjusted for all exposures together (by using missing indicators when needed). In 17 studies, grade was available for at least some serous cases. We conducted similar analyses among serous tumors by comparing risk factors for well-, moderately, and poorly differentiated tumors and unknown grade. We performed unsupervised hierarchical clustering of the four subtypes (with and without separating serous tumors by grade) with $\beta$-estimates for all exposures, except duration of breastfeeding (not significantly associated with any of the four subtypes), by using complete linkage and uncentered correlation (Pearson coefficient). SAS 9.3 software (SAS Institute, Cary, NC) was used to conduct the analyses. $P<.05$ was considered statistically significant. As a sensitivity analysis, we corrected for multiple comparisons for the test of heterogeneity by using an adjusted $\alpha$ of $.004(.05 / 13$ exposures).

\section{RESULTS}

\section{Study Population}

Among 1,284,586 participants (1,381,275 with the inclusion of full cohort size for case-cohort studies), 5,584 invasive epithelial ovarian cancers were identified during follow-up. Case numbers ranged from 1,281 for breastfeeding to 5,523 for OC use (Appendix Table A2). There were 3,378 (73.7\% of cases with known histology) serous, 606 (13.2\%) endometrioid, 331 (7.2\%) mucinous, and 269 (5.9\%) clear cell carcinomas. Fifteen of 21 cohorts were based in North America, five in Europe, and one in Asia (Table 1); approximately one half of the cohorts started enrollment in the 1990s. The median age at diagnosis was 67.0 years for serous, 63.0 years for endometrioid, 64.0 years for mucinous, and 61.3 years for clear cell carcinomas and 68.9 years for cases of unknown histology.

\section{Associations of Hormonal and Reproductive Factors}

Most reproductive and hormonal risk factors, except for breastfeeding, were associated with ovarian cancer risk overall (Table 2). Parous versus nulliparous women had a reduced risk of all ovarian cancer subtypes, with significant heterogeneity by subtype $(P$ value for heterogeneity $[P$-het $]<.001)$. The strongest risk reduction was observed for clear cell carcinomas (relative risk [RR], 0.35 ; 95\% CI, 0.27 to 0.47 ), whereas serous cancers had the least risk reduction ( $\mathrm{RR}, 0.81 ; 95 \% \mathrm{CI}, 0.73$ to 0.90$)$. Similar patterns were observed for number of children $(P$-het $<.001)$. In subtype-specific analyses, a 5-year increase in duration of OC use was associated with a significant $14 \%$ to $15 \%$ lower risk of serous, endometrioid, and clear cell carcinomas but not with mucinous tumors $(P$-het $=.04)$. Similarly, OC use for $>10$ years was associated with a $36 \%$ to $49 \%$ reduction in risk for serous, endometrioid, and clear cell tumors.

A 5-year later menopause was associated with endometrioid and clear cell carcinomas (RR, 1.19 [95\% CI, 1.05 to 1.34] and 1.37 [95\% CI, 1.15 to 1.64 ], respectively), with no association for serous and mucinous carcinomas $(P$-het $=.009)$. A 5 -year increase in menopausal HT use was associated with an increased risk of serous (RR, 1.21; 95\% CI, 1.17 to 1.25 ) and endometrioid (RR, 1.25; 95\% $\mathrm{CI}, 1.15$ to 1.36$)$ carcinomas but a reduced risk of clear cell carcinoma (RR, 0.69; 95\% CI, 0.52 to 0.92 ; $P$-het $<.001$ ). Tubal ligation was only associated with reduced risk of endometrioid (RR, 0.60; 95\% CI, 0.41 to 0.88 ) and clear cell (RR, 0.35; 95\% CI, 0.18 to $0.69 ; P$-het $<.001)$ carcinomas, whereas hysterectomy was associated with decreased risk of clear cell carcinomas (RR, 0.57; $95 \%$ CI, 0.36 to 0.88 ; $P$-het $=.006)$. Self-reported endometriosis was significantly associated only with endometrioid (RR, 2.32; 95\% CI, 1.36 to 3.95$)$ and clear cell (RR, 2.87; 95\% CI, 1.53 to 5.39; $P$-het $=.01)$ carcinomas. There was no significant heterogeneity in associations by histology for breastfeeding or age at menarche, although the latter was significantly inversely associated with clear cell carcinomas.

\section{Associations of Other Risk Factors}

Height and family history of both breast and ovarian cancer, but not smoking or BMI, were significantly associated with ovarian cancer risk overall (Table 3). A first-degree family history of breast 
Table 2. Associations of Hormonal and Reproductive Factors With Invasive Epithelial Ovarian Cancer Overall and by Subtypes in the Ovarian Cancer Cohort Consortium

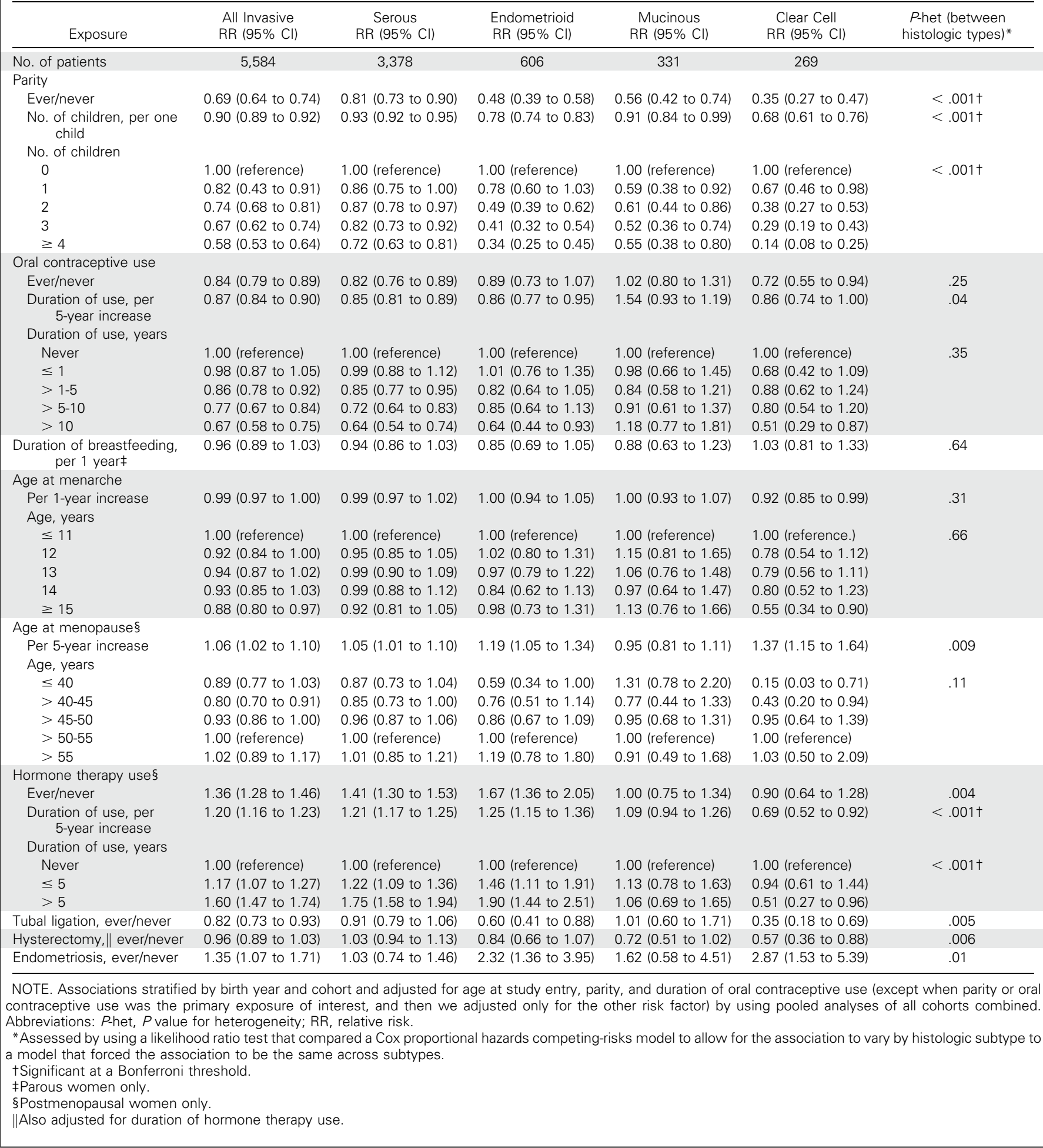

and ovarian cancer was associated with an increased risk of serous tumors (RR, $1.13[95 \% \mathrm{CI}, 1.02$ to $1.26 ; P$-het $=.008]$ and 1.61 [95\% CI, 1.32 to $1.97 ; P$-het $=.31$ ], respectively). Family history of breast cancer was also associated with endometrioid carcinomas (RR, 1.47; 95\% CI, 1.15 to 1.87). BMI was not significantly associated with ovarian carcinomas overall or with any subtype, although there was a borderline association with endometrioid carcinomas (RR per $5 \mathrm{~kg} / \mathrm{m}^{2}, 1.07 ; 95 \% \mathrm{CI}, 0.99$ to 1.16 ). Ever smoking was associated with mucinous carcinomas only (RR, 1.27; 95\% CI, 1.01 to 1.59 ); each 20 pack-years of smoking was 
associated with an increased risk of mucinous and a decreased risk of clear cell carcinomas $(P$-het $=.002)$.

\section{Associations by Subtype of Serous Carcinomas}

Among serous tumors, moderately and poorly differentiated carcinomas had similar associations, whereas associations for welldifferentiated carcinomas were qualitatively different. However, the heterogeneity was not significant for most individual factors (Table 4; Appendix Table A3, online only) for high-/moderateversus low-grade serous carcinomas. For example, endometriosis was significantly associated with well-differentiated carcinomas (RR, 3.77; 95\% CI, 1.24 to 11.48 ) but not poorly differentiated carcinomas (RR, $1.11 ; 95 \% \mathrm{CI}, 0.70$ to 1.74 ; $P$-het $=.12$ ). Similarly, $>5$ years of HT use versus never use was associated with a 2.9-fold higher risk of well-differentiated carcinomas but only an $80 \%$ higher risk of poorly differentiated carcinomas $(P$-het $=.45)$.

\section{Meta-Analysis and Heterogeneity Across Studies}

Results for meta-analyses were similar to the pooled analyses (Appendix Table A4, online only). We observed little heterogeneity in associations across studies $(P<.01$ for only 13 of 188 comparisons). All of these were for continuous variables, but the categorical associations did not show heterogeneity. Family history of ovarian cancer showed heterogeneity for all four subtypes across studies likely because of the small number of exposed cases in many studies. Results were similar when including women with a history of cancer at baseline or when all exposures were included in the model (data not shown).

\section{Integrated Analysis of Risk Factors in Ovarian Cancer Subtypes}

Each subtype had unique patterns of risk factor associations (Fig 1). The strongest associations for most factors were observed for endometrioid and clear cell tumors. Unsupervised clustering divided the four histologic subtypes into two major groups (Fig 1A). Serous carcinomas were separate from the other three subtypes (Pearson correlation, 0.19). Endometrioid and clear cell carcinomas had the most similar risk factor associations (Pearson correlation, 0.71). Serous cancers divided by grade (Fig 1B) were split into two distinct groups: well-differentiated serous carcinomas clustered with endometrioid carcinomas (Pearson correlation, 0.75), whereas moderately and poorly differentiated serous carcinomas clustered together (Pearson correlation, 0.90).

\begin{tabular}{|c|c|c|c|c|c|c|}
\hline Exposure & $\begin{array}{l}\text { All Invasive } \\
\text { RR }(95 \% \mathrm{Cl})\end{array}$ & $\begin{array}{c}\text { Serous } \\
\operatorname{RR}(95 \% \mathrm{Cl})\end{array}$ & $\begin{array}{l}\text { Endometrioid } \\
\text { RR }(95 \% \mathrm{Cl})\end{array}$ & $\begin{array}{c}\text { Mucinous } \\
\text { RR }(95 \% \mathrm{Cl})\end{array}$ & $\begin{array}{c}\text { Clear Cell } \\
\text { RR }(95 \% \mathrm{Cl})\end{array}$ & $\begin{array}{c}\text { P-het (between } \\
\text { histologic } \\
\text { types) }^{*}\end{array}$ \\
\hline No. of patients & 5,584 & 3,378 & 606 & 331 & 269 & \\
\hline $\begin{array}{l}\text { First-degree family history of } \\
\text { breast cancer, ever/never }\end{array}$ & $1.09(1.00$ to 1.19$)$ & $1.13(1.02$ to 1.26$)$ & $1.47(1.15$ to 1.87$)$ & $0.73(0.47$ to 1.13$)$ & $0.75(0.46$ to 1.22$)$ & .008 \\
\hline $\begin{array}{l}\text { First-degree family history of } \\
\text { ovarian cancer, ever/never }\end{array}$ & $1.48(1.26$ to 1.75$)$ & $1.61(1.32$ to 1.97$)$ & $0.97(0.52$ to 1.82$)$ & $1.33(0.59$ to 3.00$)$ & $0.96(0.36$ to 2.57$)$ & .31 \\
\hline \multicolumn{7}{|l|}{ Body mass index } \\
\hline Per $5 \mathrm{~kg} / \mathrm{m}^{2}$ & $1.01(0.98$ to 1.04$)$ & $0.97(0.93$ to 1.01$)$ & 1.07 (0.99 to 1.16$)$ & $1.08(0.96$ to 1.20$)$ & $1.04(0.92$ to 1.17$)$ & .06 \\
\hline \multicolumn{7}{|l|}{ Categorical, $\mathrm{kg} / \mathrm{m}^{2}$} \\
\hline$<20$ & $1.02(0.91$ to 1.13$)$ & $1.06(0.92$ to 1.21$)$ & $0.85(0.60$ to 1.19$)$ & $1.36(0.90$ to 2.04$)$ & $0.96(0.60$ to 1.53$)$ & .10 \\
\hline 20 to $<25$ & 1.00 (reference) & 1.00 (reference) & 1.00 (reference) & 1.00 (reference) & 1.00 (reference) & \\
\hline 25 to $<30$ & 0.97 (0.91 to 1.03$)$ & 0.91 (0.84 to 0.99$)$ & $0.97(0.80$ to 1.18$)$ & $1.42(1.10$ to 1.83$)$ & $1.21(0.91$ to 1.61$)$ & \\
\hline 30 to $<35$ & 0.99 (0.90 to 1.08$)$ & $0.92(0.82$ to 1.04$)$ & 1.09 (0.83 to 1.43$)$ & $1.23(0.83$ to 1.82$)$ & $0.97(0.62$ to 1.51$)$ & \\
\hline$\geq 35$ & 1.09 (0.97 to 1.24$)$ & $0.97(0.83$ to 1.14$)$ & $1.26(0.88$ to 1.80$)$ & $1.24(0.69$ to 2.21$)$ & $1.23(0.70$ to 2.15$)$ & \\
\hline \multicolumn{7}{|l|}{ Height } \\
\hline Per $0.5 \mathrm{~m}$ & 1.06 (1.04 to 1.08$)$ & 1.06 (1.03 to 1.09$)$ & $1.06(1.00$ to 1.13$)$ & $1.04(0.95$ to 1.13$)$ & $1.08(0.98$ to 1.19$)$ & .94 \\
\hline \multicolumn{7}{|l|}{ Categorical, m } \\
\hline$<1.60$ & 0.89 (0.83 to 0.96$)$ & $0.86(0.78$ to 0.95$)$ & $1.03(0.82$ to 1.29$)$ & 0.87 (0.64 to 1.18$)$ & $0.92(0.65$ to 1.30$)$ & .27 \\
\hline 1.60 to $<1.65$ & 1.00 (reference) & 1.00 (reference) & 1.00 (reference) & 1.00 (reference) & 1.00 (reference) & \\
\hline 1.65 to $<1.70$ & $1.02(0.95$ to 1.10$)$ & $1.04(0.95$ to 1.14$)$ & $0.93(0.74$ to 1.17$)$ & $0.83(0.61$ to 1.13$)$ & $0.97(0.70$ to 1.36$)$ & \\
\hline$\geq 1.70$ & $1.12(1.03$ to 1.21$)$ & $1.06(0.96$ to 1.17$)$ & 1.27 (1.01 to 1.60$)$ & $1.12(0.82$ to 1.52$)$ & 1.24 (0.88 to 1.73$)$ & \\
\hline \multicolumn{7}{|l|}{ Smoking } \\
\hline Ever/never & 0.99 (0.94 to 1.05$)$ & 0.99 (0.92 to 1.06$)$ & $0.93(0.79$ to 1.09$)$ & 1.27 (1.01 to 1.59$)$ & $0.95(0.74$ to 1.21$)$ & .14 \\
\hline Per 20 pack-years & 0.98 (0.94 to 1.02$)$ & 1.01 (0.96 to 1.06$)$ & $0.92(0.80$ to 1.06$)$ & $1.20(1.04$ to 1.39$)$ & 0.68 (0.53 to 0.89$)$ & $.002 \dagger$ \\
\hline \multicolumn{7}{|l|}{ Categorical, pack-years } \\
\hline Never & 1.00 (reference) & 1.00 (reference) & 1.00 (reference) & 1.00 (reference) & 1.00 (reference) & .09 \\
\hline$\leq 10$ & 1.07 (0.97 to 1.17$)$ & 1.07 (0.96 to 1.21$)$ & 1.02 (0.78 to 1.32$)$ & $1.14(0.78$ to 1.68$)$ & 0.95 (0.64 to 1.40$)$ & \\
\hline$>10$ to 20 & $1.02(0.90$ to 1.15$)$ & $1.04(0.89$ to 1.21$)$ & $0.72(0.49$ to 1.07$)$ & 1.40 (0.89 to 2.20$)$ & 0.88 (0.52 to 1.48$)$ & \\
\hline$>20$ to 35 & 0.96 (0.85 to 1.08$)$ & 0.99 (0.85 to 1.15$)$ & $0.92(0.65$ to 1.30$)$ & $1.16(0.72$ to 1.88$)$ & $0.44(0.22$ to 0.91$)$ & \\
\hline$>35$ & 0.99 (0.88 to 1.12$)$ & $1.08(0.93$ to 1.24$)$ & 0.85 (0.57 to 1.26$)$ & 1.60 (1.02 to 2.51$)$ & $0.42(0.18$ to 0.94$)$ & \\
\hline
\end{tabular}

NOTE. Associations stratified by birth year and cohort and adjusted for age at study entry, parity, and duration of oral contraceptive use (except when parity or ora contraceptive use was the primary exposure of interest, and then we adjusted only for the other risk factor) by using a pooled analysis of all cohorts combined. Abbreviations: $P$-het, $P$ value for heterogeneity; RR, relative risk.

${ }^{*}$ Assessed by using a likelihood ratio test that compared a Cox proportional hazards competing-risks model to allow for the association to vary by histologic subtype to a model that forced the association to be the same across subtypes.

tSignificant at a Bonferroni threshold. 
Table 4. Associations of Risk Factors Among Serous Ovarian Carcinomas by Grade in the Ovarian Cancer Cohort Consortium

\begin{tabular}{|c|c|c|c|c|c|}
\hline \multirow[b]{2}{*}{ Exposure } & \multicolumn{4}{|c|}{ Grade, RR (95\% Cl) } & \multirow[b]{2}{*}{ P-hett } \\
\hline & Well Differentiated* & Moderately Differentiated & Poorly Differentiated & Unknown & \\
\hline \multicolumn{6}{|l|}{ Parity } \\
\hline \multicolumn{6}{|l|}{ No. of children } \\
\hline 0 & 1.00 (reference) & 1.00 (reference) & 1.00 (reference) & 1.00 (reference) & \\
\hline 1 & 0.84 (0.41 to 1.73$)$ & 0.90 (0.64 to 1.27$)$ & 0.85 (0.69 to 1.05$)$ & $0.94(0.70$ to 1.26$)$ & \\
\hline$\geq 4$ & $0.45(0.22$ to 0.91$)$ & $0.68(0.50$ to 0.92$)$ & $0.69(0.58$ to 0.82$)$ & 0.89 (0.69 to 1.14$)$ & \\
\hline \multicolumn{6}{|l|}{ Oral contraceptive use } \\
\hline Ever/never & $1.11(0.72$ to 1.72$)$ & $0.80(0.65$ to 0.98$)$ & 0.85 (0.76 to 0.95$)$ & $0.77(0.66$ to 0.90$)$ & .36 \\
\hline Duration of use, per 5-year increase & $0.79(0.62$ to 1.00$)$ & $0.82(0.73$ to 0.92$)$ & $0.90(0.84$ to 0.96$)$ & $0.77(0.69$ to 0.87$)$ & .09 \\
\hline \multicolumn{6}{|l|}{ Duration of use, years } \\
\hline Never & 1.00 (reference) & 1.00 (reference) & 1.00 (reference) & 1.00 (reference) & \\
\hline$\leq 1$ & $1.80(0.98$ to 3.30$)$ & 0.90 (0.63 to 1.29$)$ & $1.01(0.84$ to 1.20$)$ & $0.96(0.74$ to 1.24$)$ & \\
\hline \multicolumn{6}{|l|}{ Age at menarche } \\
\hline Per 1-year increase & $1.01(0.91$ to 1.11$)$ & 1.00 (0.94 to 1.06$)$ & $1.01(0.98$ to 1.04$)$ & $0.95(0.91$ to 1.00$)$ & .21 \\
\hline \multicolumn{6}{|l|}{ Age, years } \\
\hline$\leq 11$ & 1.00 (reference) & 1.00 (reference) & 1.00 (reference) & 1.00 (reference) & \\
\hline 12 & $1.26(0.70$ to 2.28$)$ & 0.86 (0.64 to 1.14$)$ & $1.06(0.91$ to 1.23$)$ & $0.86(0.69$ to 1.06$)$ & \\
\hline 13 & 1.37 (0.83 to 2.28$)$ & $0.94(0.73$ to 1.20$)$ & 1.10 (0.96 to 1.26$)$ & $0.76(0.62$ to 0.92$)$ & .22 \\
\hline 14 & 1.20 (0.62 to 2.34$)$ & $0.86(0.62$ to 1.18$)$ & $1.16(0.97$ to 1.38$)$ & $0.83(0.65$ to 1.05$)$ & \\
\hline$\geq 15$ & 1.00 (0.49 to 2.05$)$ & $0.99(0.72$ to 1.36$)$ & $0.94(0.78$ to 1.14$)$ & $0.80(0.62$ to 1.02$)$ & \\
\hline \multicolumn{6}{|l|}{ Age at menopause } \\
\hline Per 5-year increase & $1.54(1.23$ to 1.91$)$ & $1.04(0.93$ to 1.16$)$ & $1.03(0.97$ to 1.10$)$ & $1.05(0.95$ to 1.16$)$ & .06 \\
\hline \multicolumn{6}{|l|}{ Age, years } \\
\hline$\leq 45$ & 0.20 (0.07 to 0.56$)$ & $0.92(0.66$ to 1.28$)$ & 0.91 (0.77 to 1.09 ) & 0.89 (0.69 to 1.17$)$ & \\
\hline$>45-50$ & 0.49 (0.29 to 0.84$)$ & 1.21 (0.94 to 1.56$)$ & $0.96(0.83$ to 1.10$)$ & $0.98(0.80$ to 1.21$)$ & .02 \\
\hline$>50-55$ & 1.00 (reference) & 1.00 (reference) & 1.00 (reference) & 1.00 (reference) & \\
\hline Hysterectomy, ever/never\| & 0.87 (0.53 to 1.43$)$ & 1.05 (0.84 to 1.33$)$ & $1.01(0.89$ to 1.14$)$ & $1.04(0.87$ to 1.25$)$ & .90 \\
\hline Endometriosis, yes/no & $3.77(1.24$ to 11.48$)$ & $1.54(0.72$ to 3.30$)$ & $1.11(0.70$ to 1.74$)$ & $0.57(0.18$ to 1.80$)$ & .12 \\
\hline First-degree family history of breast cancer, yes/no & $1.23(0.71$ to 2.15$)$ & $1.20(0.91$ to 1.58$)$ & $1.12(0.97$ to 1.30$)$ & $0.96(0.76$ to 1.21$)$ & .58 \\
\hline First-degree family history of ovarian cancer, yes/no & $0.90(0.22$ to 3.70$)$ & $1.46(0.83$ to 2.54$)$ & 1.63 (1.25 to 2.13$)$ & 1.64 (1.08 to 2.47$)$ & .82 \\
\hline \multicolumn{6}{|l|}{ Body mass index } \\
\hline Per $5 \mathrm{~kg} / \mathrm{m}^{2}$ & $0.92(0.74$ to 1.14$)$ & 0.99 (0.90 to 1.08$)$ & $0.92(0.87$ to 0.97$)$ & $1.05(0.97$ to 1.13$)$ & .03 \\
\hline Categorical, kg/m² & & & & & \\
\hline$<20$ & $1.33(0.67$ to 2.62$)$ & $0.78(0.51$ to 1.19$)$ & $1.15(0.95$ to 1.39$)$ & $1.11(0.83$ to 1.49$)$ & \\
\hline 20 to $<25$ & 1.00 (reference) & 1.00 (reference) & 1.00 (reference) & 1.00 (reference) & \\
\hline 25 to $<30$ & $1.02(0.65$ to 1.59$)$ & 1.08 (0.88 to 1.33$)$ & $0.84(0.74$ to 0.94$)$ & $0.89(0.75$ to 1.05$)$ & .22 \\
\hline 30 to $<35$ & 0.85 (0.44 to 1.66$)$ & 0.98 (0.73 to 1.32$)$ & $0.85(0.72$ to 1.00$)$ & $1.04(0.83$ to 1.32$)$ & \\
\hline$\geq 35$ & $1.15(0.51$ to 2.59$)$ & 0.88 (0.56 to 1.39$)$ & $0.88(0.70$ to 1.10$)$ & $1.25(0.92$ to 1.70$)$ & \\
\hline Height & & & & & \\
\hline Per $0.5 \mathrm{~m}$ & $1.05(0.93$ to 1.18$)$ & $1.06(0.99$ to 1.14$)$ & $1.07(1.03$ to 1.11$)$ & $1.03(0.97$ to 1.08$)$ & .72 \\
\hline Categorical, $\mathrm{m}$ & & & & & \\
\hline$<1.60$ & $0.83(0.49$ to 1.39$)$ & $0.92(0.72$ to 1.17$)$ & $0.82(0.72$ to 0.95$)$ & $1.00(0.82$ to 1.21$)$ & \\
\hline 1.60 to $<1.65$ & 1.00 (reference) & 1.00 (reference) & 1.00 (reference) & 1.00 (reference) & .70 \\
\hline 1.65 to $<1.70$ & $1.21(0.75$ to 1.95$)$ & $1.03(0.81$ to 1.30$)$ & $1.03(0.91$ to 1.18$)$ & 1.15 (0.95 to 1.39$)$ & \\
\hline$\geq 1.70$ & 0.96 (0.55 to 1.69$)$ & $1.08(0.83$ to 1.41$)$ & $1.06(0.92$ to 1.22$)$ & $0.96(0.77$ to 1.20$)$ & \\
\hline & (continued & following page) & & & \\
\hline
\end{tabular}




\begin{tabular}{|c|c|c|c|c|c|}
\hline \multirow[b]{2}{*}{ Exposure } & \multicolumn{4}{|c|}{ Grade, RR $(95 \% \mathrm{Cl})$} & \multirow[b]{2}{*}{$P$-het† } \\
\hline & Well Differentiated* & Moderately Differentiated & Poorly Differentiated & Unknown & \\
\hline \multicolumn{6}{|l|}{ Smoking } \\
\hline Ever/never & $1.10(0.85$ to 1.41$)$ & 0.95 (0.84 to 1.07$)$ & $0.96(0.90$ to 1.03$)$ & 1.04 (0.95 to 1.15$)$ & .38 \\
\hline Continuous pack-years, per 20 pack-years & $0.87(0.59$ to 1.26$)$ & $1.00(0.87$ to 1.15$)$ & $0.98(0.92$ to 1.05$)$ & 1.07 (0.97 to 1.18$)$ & .44 \\
\hline \multicolumn{6}{|l|}{ Categorical, pack-years } \\
\hline Never & 1.00 (reference) & 1.00 (reference) & 1.00 (reference) & & \multirow{3}{*}{.91} \\
\hline$\leq 20$ & 1.20 (0.70 to 2.08$)$ & 1.00 (0.76 to 1.32$)$ & 1.08 (0.94 to 1.24$)$ & 1.10 (0.88 to 1.36$)$ & \\
\hline$>20$ & $0.72(0.34$ to 1.52$)$ & $0.97(0.71$ to 1.31$)$ & $1.03(0.89$ to 1.21$)$ & 1.09 (0.87 to 1.38$)$ & \\
\hline \multicolumn{6}{|c|}{$\begin{array}{l}\text { NOTE. Associations stratified by birth year and cohort and adjusted for age at study entry, parity, and duration of oral contraceptive use (except when parity or oral } \\
\text { contraceptive use was the primary exposure of interest, and then we adjusted only for the other risk factor) by using pooled analyses of all cohorts combined. Five cohorts } \\
\text { with no information on grade for any ovarian cancer cases were excluded. Abbreviation: P-het, } P \text { value for heterogeneity; RR, relative risk. } \\
\text { *Number of cases ranged from } 28 \text { (breastfeeding) to } 121 \text { (oral contraceptive use) for well-differentiated, } 113 \text { (endometriosis) to } 496 \text { (oral contraceptive use) for } \\
\text { moderately differentiated, } 338 \text { (breastfeeding) to } 1,637 \text { (oral contraceptive use) for poorly differentiated, and } 141 \text { (endometriosis) to } 773 \text { (oral contraceptive use) for } \\
\text { unknown grade. } \\
\text { †Assessed by using a likelihood ratio test that compared a Cox proportional hazards competing-risks model to allow for the association to vary by grade to a model that } \\
\text { forced the association to be the same across grades. } \\
\ddagger \text { Parous women only. } \\
\text { §Postmenopausal women only. } \\
\text { ॥Also adjusted for duration of hormone therapy use. }\end{array}$} \\
\hline
\end{tabular}

\section{DISCUSSION}

In a large pooled analysis of $>1.3$ million women, we investigated 14 established or putative risk factors in ovarian cancer subtypes. Nine risk factors had significant heterogeneity across subtypes. Most reproductive and hormonal risk factors had stronger associations with endometrioid and clear cell carcinomas compared with the other types. Serous and poorly differentiated carcinomas, the most common and aggressive subtypes, had modest associations only with parity, OC use, menopausal HT use, and family history of breast cancer and stronger associations with family history of ovarian cancer.

The current analysis represents, to our knowledge, the largest comprehensive and prospective evaluation of ovarian cancer risk factors by histologic subtypes. The results are consistent with previous reports from individual prospective studies within the OC3 (ie, Nurses' Health Study/Nurses' Health Study II, National Institutes of Health-AARP Diet and Health Study, European Prospective Investigation Into Cancer). ${ }^{15-17}$ However, individually, these studies were underpowered to assess subtype-specific associations, particularly for rare types. Previously, other consortia, largely based on case-control studies, reported subtype-specific associations for individual risk factors ${ }^{12-14,19-21}$ similar to what we observed.

Models of ovarian carcinogenesis have separated epithelial tumors into major pathways with distinct cells of origin, carcinogenic pathways, and histology with different clinical behavior. $^{8,10}$ An integrated evaluation of ovarian cancer risk factors by subtypes is important to understand factors that drive these etiologic pathways on the population level. Each subtype had a qualitatively unique pattern of associations, and serous carcinomas were clearly separated from endometrioid, clear cell, and mucinous carcinomas. Although endometrioid and clear cell carcinomas had qualitatively similar associations for 10 risk factors, they differed in associations related to HT use (which went in opposite directions), family history of breast cancer (associated with endometrioid only), as well as age at menarche and smoking (associated with clear cell only). Every reproductive/ hormonal factor, except breastfeeding, was significantly associated with clear cell tumors.

The present results suggest that currently hypothesized, unifying mechanisms, such as incessant ovulation, ${ }^{4}$ do not apply equally to ovarian cancers. Several variables that determine a woman's lifetime number of ovulations had significant heterogeneity across subtypes. Only parity and height were associated with all subtypes, which suggests a common biologic effect. $^{22}$ Of note, mucinous tumors were not associated with any ovulation-related factors except parity, which suggests a more distinct etiology.

Ovarian cancer subtypes share some risk factors with other cancer sites. The inverse association between smoking and clear cell ovarian carcinomas is similar to that for endometrial cancer. ${ }^{23}$ Mucinous ovarian cancers share histologic appearance and an association with smoking with colorectal cancers. ${ }^{24}$ Serous ovarian cancers had weaker associations with most hormonal and reproductive factors compared with nonserous cancers (with the exception of OC use), which is similar to associations for hormone receptor-negative breast cancers. ${ }^{25}$ These similarities of risk factor associations across cancers mirror molecular data that showed that tumor subtypes from different organs may be more similar to one another on the molecular level compared with other subtypes at the same site (eg, high-grade serous ovarian cancer, basal-like breast cancer). ${ }^{26}$

Although the subtype-specific associations observed in the current study strongly corroborate the etiologic heterogeneity of ovarian cancers, a purely histology-based classification of end points may have limitations. ${ }^{27}$ Histologic evaluation is subjective, and pathology practice changes over time, which could affect subtype distributions by location and year of diagnosis. We observed heterogeneity among studies for four risk factors among mucinous tumors, which were possibly related to temporal and geographic differences in defining mucinous tumors. However, overall, we did not observe significant differences in subtype 


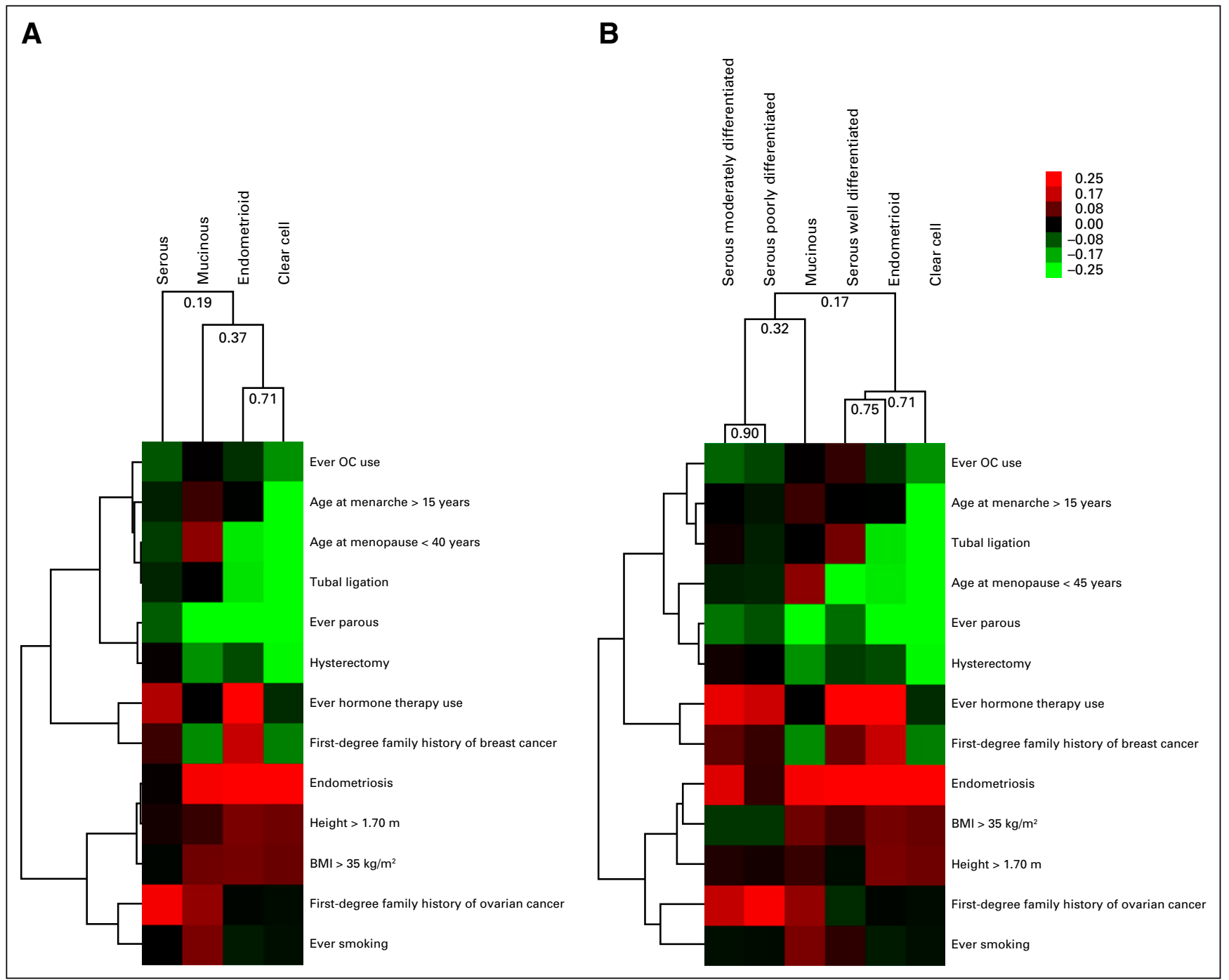

Fig 1. Unsupervised hierarchical clustering of ovarian cancer histologic subtypes by their associations with risk factors. Unsupervised hierarchical clustering of the (A) four subtypes and (B) that includes the serous subtype divided into well-, moderately, and poorly differentiated carcinomas by using $\beta$-estimates, complete linkage, and an uncentered correlation similarity metric. The categories used in the cluster analysis were ever versus never parous, ever versus never oral contraceptive (OC) use, ever versus never tubal ligation, ever versus never endometriosis, age at menarche $>15 v \leq 11$ years, age at menopause $<40$ versus 50 to 55 years, ever versus never menopausal hormone therapy use, ever versus never hysterectomy, family history of breast cancer (yes $v$ no), family history of ovarian cancer (yes $v$ no), body mass index (BMI) $>35$ versus 20 to $25 \mathrm{~kg} / \mathrm{m}^{2}$, height (per $5-\mathrm{cm}$ increase), and ever versus never smoking. The color scale shows the range of $\beta$-values for each exposure.

proportions across studies or over time (data not shown). Unsupervised clustering demonstrated that well-differentiated serous carcinomas were distinct from higher grade serous carcinomas and grouped with endometrioid carcinomas. This is important etiologically and further supports the differentiation of these two groups of serous carcinomas as proposed in models based on somatic mutations. ${ }^{89}$ However, in population-based studies, the grade reported on pathology reports may not be reliable, and low-grade serous carcinomas account for only approximately $5 \%$ of all serous cancers, ${ }^{28}$ which limits potential misclassification when associations for all serous carcinomas are considered together. ${ }^{29}$ Analyses by tumor aggressiveness and tumor dominance have also shown differences in risk factor associations, which indicates important biologic heterogeneity beyond histologic subtypes. ${ }^{30,31}$ Furthermore, additional molecular subgroups have been described within high-grade serous ovarian cancers, ${ }^{32,33}$ but thus far, based on small studies, these subtypes have shown only limited heterogeneity in risk factor associations. $^{34}$

In summary, we conducted the largest integrated prospective analysis of ovarian cancer risk factors to date. Most factors showed heterogeneity across histologic subtypes, and each subtype had unique patterns of risk factor associations. The results have important implications with respect to etiology and prevention of ovarian cancers. OCs continue to be an important preventive factor for most types of ovarian cancer. Few other risk factors for ovarian cancer are modifiable, and those that are, such as smoking and obesity, did not show clear associations with serous carcinomas, the most common and fatal subtype. The substantial heterogeneity of individual risk factor associations across ovarian cancer subtypes supports that subtypes are indeed different diseases and underscores the importance of evaluating risk factors and biomarkers 
by ovarian cancer subtypes. ${ }^{35-37}$ Our work has implications for the development of risk prediction models, which generally consider ovarian cancer as a whole. ${ }^{38}$ Due to weaker associations observed for high-grade serous carcinomas, prediction of the clinically most important subtype may perform worse than for other types, which underscores the importance of finding better risk factors for serous carcinomas. Evaluation of subtype-specific risk factor associations is important to gain a better understanding of ovarian cancer etiology and for targeted development of novel prevention approaches; these analyses require pooling of data across many studies in consortia. To this end, future work in the OC3 will include an evaluation of circulating biomarkers, such as inflammation markers, by ovarian cancer subtypes and the development of risk prediction models that integrate risk factor information and genetic data that account for the heterogeneity of ovarian cancer. Furthermore, we and others should explore potential risk factors for high-grade serous cancers, which showed the weakest associations for most established ovarian cancer risk factors.

\section{AUTHORS' DISCLOSURES OF POTENTIAL CONFLICTS OF INTEREST}

Disclosures provided by the authors are available with this article at www.jco.org.

\section{AUTHOR CONTRIBUTIONS}

Conception and design: Nicolas Wentzensen, Elizabeth M. Poole, V. Wendy Setiawan, Kala Visvanathan, Patricia Hartge, Antonia Trichopoulou, Shelley S. Tworoger

Financial support: Shelley S. Tworoger

Administrative support: Louise K. Sjöholm, Shelley S. Tworoger

Provision of study materials: Nicolas Wentzensen, Leslie Bernstein, Eva Lundin, Kim Robien, Leo J. Schouten, Louise K. Sjöholm, Shelley S.

Tworoger

Collection and assembly of data: Nicolas Wentzensen, Elizabeth M. Poole, Britton Trabert, Emily White, Alan A. Arslan, Alpa V. Patel, V. Wendy Setiawan, Kala Visvanathan, Elisabete Weiderpass, Hans-Olov Adami, Saioa Chamosa, Tess V. Clendenen, Annika Idahl, Victoria Kirsh, WoonPuay Koh, Eva Lundin, Catherine Schairer, Leo J. Schouten, Louise K. Sjöholm, Anthony Swerdlow, Ruth Travis, Shelley S. Tworoger

Data analysis and interpretation: Nicolas Wentzensen, Elizabeth $\mathrm{M}$. Poole; Britton Trabert, Emily White, Alpa V. Patel, V. Wendy Setiawan, Kala Visvanathan, Elisabete Weiderpass, Hans-Olov Adami, Amanda Black, Leslie Bernstein, Louise A. Brinton, Julie Buring, Lesley M. Butler, Laure Dossus, Renee Fortner, Susan M. Gapstur, Mia M. Gaudet, Inger T. Gram, Patricia Hartge, Judith Hoffman-Bolton, Annika Idahl, Michael Jones, Rudolf Kaaks, James V. Lacey Jr, I-Min Lee, Eva Lundin, Melissa A. Merritt, N. Charlotte Onland-Moret, Ulrike Peters, Jenny N. Poynter, Sabina Rinaldi, Kim Robien, Thomas Rohan, Dale P. Sandler, Leo J. Schouten, Sabina Sieri, Anna Tjonneland, Piet A. van den Brandt, Lynne Wilkens, Alicja Wolk, Hannah P. Yang, Anne Zeleniuch-Jacquotte, Shelley S. Tworoger

Manuscript writing: All authors

Final approval of manuscript: All authors

\section{REFERENCES}

1. Ferlay J, Soerjomataram I, Dikshit $\mathrm{R}$, et al: Cancer incidence and mortality worldwide: Sources, methods and major patterns in GLOBOCAN 2012. Int J Cancer 136:E359-E386, 2015

2. Buys SS, Partridge E, Black A, et al: Effect of screening on ovarian cancer mortality: The Prostate, Lung, Colorectal and Ovarian (PLCO) Cancer Screening Randomized Controlled Trial. JAMA 305: 2295-2303, 2011

3. Jacobs IJ, Menon U, Ryan A, et al: Ovarian cancer screening and mortality in the UK Collaborative Trial of Ovarian Cancer Screening (UKCTOCS): A randomised controlled trial. Lancet 387:945-956, 2016

4. Fathalla MF: Incessant ovulation-a factor in ovarian neoplasia. Lancet 2:163, 1971

5. Ness RB, Cottreau C: Possible role of ovarian epithelial inflammation in ovarian cancer. J Natl Cancer Inst 91:1459-1467, 1999

6. Rice MS, Hankinson SE, Tworoger SS: Tubal ligation, hysterectomy, unilateral oophorectomy, and risk of ovarian cancer in the Nurses' Health Studies. Fertil Steril 102:192-198, 2014

7. Trabert $B$, Ness RB, Lo-Ciganic WH, et al: Aspirin, nonaspirin nonsteroidal anti-inflammatory drug, and acetaminophen use and risk of invasive epithelial ovarian cancer: A pooled analysis in the Ovarian Cancer Association Consortium. J Natl Cancer Inst 106:djt431, 2014

8. Jarboe EA, Folkins AK, Drapkin $R$, et al: Tubal and ovarian pathways to pelvic epithelial cancer: a pathological perspective. Histopathology 55:619, 2009
9. Kurman RJ, Shih leM: Molecular pathogenesis and extraovarian origin of epithelial ovarian cancer-shifting the paradigm. Hum Pathol 42: 918-931, 2011

10. Steffensen $K D$, Waldstrøm $M$, Grove $A$, et al: Improved classification of epithelial ovarian cancer: Results of 3 Danish cohorts. Int J Gynecol Cancer 21: 1592-1600, 2011

11. Collaborative Group on Epidemiological Studies of Ovarian Cancer: Ovarian cancer and body size: Individual participant meta-analysis including 25,157 women with ovarian cancer from 47 epidemiological studies. PLoS Med 9:e1001200, 2012

12. Beral V, Doll R, Hermon $C$, et al: Ovarian cancer and oral contraceptives: Collaborative reanalysis of data from 45 epidemiological studies including 23,257 women with ovarian cancer and 87,303 controls. Lancet 371:303-314, 2008

13. Beral V, Gaitskell K, Hermon C, et al: Ovarian cancer and smoking: Individual participant metaanalysis including 28,114 women with ovarian cancer from 51 epidemiological studies. Lancet Oncol 13:946-956, 2012

14. Beral V, Gaitskell K, Hermon C, et al: Menopausal hormone use and ovarian cancer risk: Individual participant meta-analysis of 52 epidemiological studies. Lancet 385:1835-1842, 2015

15. Fortner RT, Ose J, Merritt MA, et al: Reproductive and hormone-related risk factors for epithelial ovarian cancer by histologic pathways, invasiveness and histologic subtypes: Results from the EPIC cohort. Int J Cancer 137:1196-1208, 2015

16. Gates MA, Rosner BA, Hecht JL, et al: Risk factors for epithelial ovarian cancer by histologic subtype. Am J Epidemiol 171:45-53, 2010
17. Yang HP, Trabert B, Murphy MA, et al: Ovarian cancer risk factors by histologic subtypes in the $\mathrm{NIH}$ AARP Diet and Health Study. Int J Cancer 131: 938-948, 2012

18. Lunn M, McNeil D: Applying Cox regression to competing risks. Biometrics 51:524-532, 1995

19. Olsen CM, Nagle CM, Whiteman DC, et al: Obesity and risk of ovarian cancer subtypes: Evidence from the Ovarian Cancer Association Consortium. Endocr Relat Cancer 20:251-262, 2013

20. Pearce $C L$, Templeman $C$, Rossing MA, et al: Association between endometriosis and risk of histological subtypes of ovarian cancer: A pooled analysis of case-control studies. Lancet Oncol 13: 385-394, 2012

21. Schouten LJ, Rivera C, Hunter DJ, et al: Height, body mass index, and ovarian cancer: A pooled analysis of 12 cohort studies. Cancer Epidemiol Biomarkers Prev 17:902-912, 2008

22. Adami HO, Hsieh CC, Lambe M, et al: Parity, age at first childbirth, and risk of ovarian cancer. Lancet 344:1250-1254, 1994

23. Setiawan WW, Yang HP, Pike MC, et al: Type I and II endometrial cancers: Have they different risk factors. J Clin Oncol 31:2607-2618, 2013

24. Newcomb PA, Storer BE, Marcus PM: Cigarette smoking in relation to risk of large bowel cancer in women. Cancer Res 55:4906-4909, 1995

25. Yang XR, Chang-Claude J, Goode EL, et al: Associations of breast cancer risk factors with tumor subtypes: A pooled analysis from the Breast Cancer Association Consortium studies. J Natl Cancer Inst 103:250-263, 2011

26. Cancer Genome Atlas Network: Comprehensive molecular portraits of human breast tumours. Nature 490:61-70, 2012 
27. Köbel M, Bak J, Bertelsen $\mathrm{BI}$, et al: Ovarian carcinoma histotype determination is highly reproducible, and is improved through the use of immunohistochemistry. Histopathology 64:1004-1013, 2014

28. Matsuno RK, Sherman ME, Visvanathan $K$, et al: Agreement for tumor grade of ovarian carcinoma: Analysis of archival tissues from the surveillance, epidemiology, and end results residual tissue repository. Cancer Causes Control 24:749-757, 2013

29. Vang R, Shih leM, Kurman RJ: Ovarian lowgrade and high-grade serous carcinoma: Pathogenesis, clinicopathologic and molecular biologic features, and diagnostic problems. Adv Anat Pathol 16: 267-282, 2009

30. Kotsopoulos J, Terry KL, Poole EM, et al: Ovarian cancer risk factors by tumor dominance, a surrogate for cell of origin. Int J Cancer 133:730-739, 2013
31. Poole EM, Merritt MA, Jordan SJ, et al: Hormonal and reproductive risk factors for epithelial ovarian cancer by tumor aggressiveness. Cancer Epidemiol Biomarkers Prev 22:429-437, 2013

32. Cancer Genome Atlas Research Network: Integrated genomic analyses of ovarian carcinoma. Nature 474:609-615, 2011

33. Tothill RW, Tinker AV, George J, et al: Novel molecular subtypes of serous and endometrioid ovarian cancer linked to clinical outcome. Clin Cancer Res 14:5198-5208, 2008

34. Schildkraut JM, Iversen ES, Akushevich L, et al: Molecular signatures of epithelial ovarian cancer: Analysis of associations with tumor characteristics and epidemiologic risk factors. Cancer Epidemiol Biomarkers Prev 22:1709-1721, 2013

35. Levine DA, Karlan BY, Strauss JF III: Evolving approaches in research and care for ovarian cancers: A report from the National Academies of Sciences,
Engineering, and Medicine. JAMA, 315:1943-1944, 2016

36. Trabert $B$, Pinto $L$, Hartge $P$, et al: Prediagnostic serum levels of inflammation markers and risk of ovarian cancer in the Prostate, Lung, Colorectal and Ovarian Cancer (PLCO) screening trial. Gynecol Oncol 135:297-304, 2014

37. Trabert $B$, Brinton $L A$, Anderson $G L$, et al: Circulating estrogens and postmenopausal ovarian cancer risk in the Women's Health Initiative Observational Study. Cancer Epidemiol Biomarkers Prev, 10.1158/1055-9965.EPI-15-1272-T [epub ahead of print on February 5, 2016]

38. Pfeiffer RM, Park $Y$, Kreimer AR, et al: Risk prediction for breast, endometrial, and ovarian cancer in white women aged 50 y or older: Derivation and validation from populationbased cohort studies. PLoS Med 10:e1001492, 2013

\section{Affiliations}

Nicolas Wentzensen, Britton Trabert, Amanda Black, Louise A. Brinton, Patricia Hartge, Catherine Schairer, and Hannah P. Yang, National Cancer Institute; Dale P. Sandler, National Institute of Environmental Health Science, Bethesda, MD; Elizabeth M. Poole, Julie Buring, I-Min Lee, and Shelley S. Tworoger, Brigham and Women's Hospital; Elizabeth M. Poole, Hans-Olov Adami, Julie Buring, I-Min Lee, and Shelley S. Tworoger, Harvard University, Boston, MA; Emily White and Ulrike Peters, Fred Hutchinson Cancer Research Center, Seattle, WA; Alan A. Arslan, Tess V. Clendenen, and Anne Zeleniuch-Jacquotte, New York University School of Medicine; Thomas Rohan, Albert Einstein College of Medicine, New York, NY; Alpa V. Patel, Susan M. Gapstur, and Mia M. Gaudet, American Cancer Society, Atlanta, GA; V. Wendy Setiawan, University of Southern California, Los Angeles; Leslie Bernstein and James V. Lacey Jr, City of Hope, Duarte, CA; Kala Visvanathan and Judith Hoffman-Bolton, Johns Hopkins Bloomberg School of Public Health, Baltimore, MD; Elisabete Weiderpass and Inger T. Gram, University of Tromsø-The Arctic University of Norway, Tromsø; Elisabete Weiderpass, Cancer Registry of Norway, Oslo, Norway; Elisabete Weiderpass, Hans-Olov Adami, Louise K. Sjöholm, and Alicja Wolk, Karolinska Institute; Stockholm; Annika Idahl and Eva Lundin, Umeå University, Umeå, Sweden; Elisabete Weiderpass, Folkhälsan Research Center, Helsinki, Finland; Lesley M. Butler, University of Pittsburgh, Pittsburgh, PA; Saioa Chamosa, BioDonostia Research Institute, San Sebastian, Spain; Laure Dossus, French Institute of Health and Medical Research, Paris; Sabina Rinaldi, International Agency for Research on Cancer, Lyon, France; Renee Fortner and Rudolf Kaaks, German Cancer Research Center, Heidelberg, Germany; Michael Jones and Anthony Swerdlow, The Institute of Cancer Research; Melissa A. Merritt, Imperial College of London, London; Ruth Travis, University of Oxford, Oxford, United Kingdom; Victoria Kirsh, University of Toronto, Toronto, Ontario, Canada; Woon-Puay Koh, Duke University, Singapore; N. Charlotte Onland-Moret, University Medical Center Utrecht, Utrecht; Leo J. Schouten and Piet A. van den Brandt, Maastricht University, Maastricht, the Netherlands; Jenny N. Poynter, University of Minnesota, Minneapolis, MN; Kim Robien, George Washington University, Washington, DC; Sabina Sieri, National Cancer Institute, Rome, Italy; Anna Tjonneland, Danish Cancer Society, Copenhagen, Denmark; Antonia Trichopoulou, Hellenic Health Foundation, Athens, Greece; and Lynne Wilkens, University of Hawaii Cancer Center, Honolulu, HI.

\section{Support}

Supported by Department of Defense Ovarian Cancer Research Program Grant No. W81XWH-12-1-0561. The UK Breakthrough Generations Study is supported by Breakthrough Breast Cancer and the Institute of Cancer Research. The Institute for Cancer Research is supported by National Health Service funding to the National Institute for Health Research Biomedical Research Centre. Also supported by K05 CA154337 from the National Cancer Institute (NCI) and Office of Dietary Supplements (VITAL [Vitamins and Lifestyle study cohort]); R01 CA39742 (Iowa Women's Health Study); National Institutes of Health/NCI grant UM1 CA182876 (Singapore Chinese Health Study); CA047988, HL043851, HL080467, and HL099355 (Women's Health Study); CA164973 (Multiethnic Cohort); R01 CA77398 and UM1 CA169417 (California Teachers Study); UM1 CA186107, P01 CA87969, UM1 CA176726, and R01 CA67262 (Nurses' Health Study, Nurses' Health Study II); grants from the Swedish Cancer Society and Swedish Research Council (Swedish Women's Lifestyle and Health cohort study); and the Swedish Research Council (Swedish Mammography Cohort). All aspects of the Cancer Prevention Study II were funded by the Intramural Research Program of the American Cancer Society and by the NCI Intramural Research Program, Intramural Research Program of the National Institutes of Health, and National Institute of Environmental Health Sciences (Z01ES044005; Sister Study). The coordination of European Prospective Investigation Into Cancer (EPIC) is supported by the European Commission (DG-SANCO) and the International Agency for Research on Cancer. The national cohorts are supported by the Danish Cancer Society (Denmark); Ligue Contre le Cancer, Institut Gustave Roussy, Mutuelle Générale de l'Education Nationale, and Institut National de la Santé et de la Recherche Médicale (France); German Cancer Aid, German Cancer Research Center, and Federal Ministry of Education and Research (Germany); Hellenic Health Foundation (Greece); Associazione Italiana per la Ricerca sul Cancro-Italy and National Research Council (Italy); Dutch Ministry of Public Health, Welfare and Sports, Netherlands Cancer Registry, LK Research Funds, Dutch Prevention Funds, Dutch Zorg Onderzoek Nederland, World Cancer Research Fund, and Statistics Netherlands (the Netherlands); Nordic Centre of 
Excellence Programme on Food, Nutrition and Health (Norway); Health Research Fund, PI13/00061 to Granada, regional governments of Spain (Andalucía, Asturias, Basque Country, Murcia [No. 6236], and Navarra), and Instituto San Carlos III Las Redes Temáticas de Investigación Cooperativa en Salud (RD06/0020; Spain); Swedish Cancer Society, Swedish Scientific Council, and County Councils of Skåne and Västerbotten (Sweden); and Cancer Research UK (14136 to EPIC-Norfolk, C570/A16491 to EPIC-Oxford) and Medical Research Council (1000143 to EPIC-Norfolk; United Kingdom).

\section{Check Out the Latest Additions to ASCO's Bookstore Today}

Learn about the latest eLearning, self-assessment, maintenance of certification, CME-accredited, and patient education products offered by ASCO. New products are added each month at asco.org/store. 


\section{AUTHORS' DISCLOSURES OF POTENTIAL CONFLICTS OF INTEREST}

Ovarian Cancer Risk Factors by Histologic Subtype: An Analysis From the Ovarian Cancer Cohort Consortium

The following represents disclosure information provided by authors of this manuscript. All relationships are considered compensated. Relationships are self-held unless noted. I = Immediate Family Member, Inst = My Institution. Relationships may not relate to the subject matter of this manuscript. For more information about ASCO's conflict of interest policy, please refer to www.asco.org/rwc or jco.ascopubs.org/site/ifc.

\section{Nicolas Wentzensen}

No relationship to disclose

Elizabeth M. Poole

No relationship to disclose

\section{Britton Trabert}

No relationship to disclose

\section{Emily White}

No relationship to disclose

Alan A. Arslan

No relationship to disclose

Alpa V. Patel

No relationship to disclose

V. Wendy Setiawan

No relationship to disclose

Kala Visvanathan

Patents, Royalties, Other Intellectual Property: Licensing of patent with Cepheid (Inst)

\section{Elisabete Weiderpass}

No relationship to disclose

Hans-Olov Adami

No relationship to disclose

Amanda Black

No relationship to disclose

Leslie Bernstein

No relationship to disclose

Louise A. Brinton

No relationship to disclose

\section{Julie Buring}

No relationship to disclose

\section{Lesley M. Butler}

No relationship to disclose

\section{Saioa Chamosa}

No relationship to disclose

Tess V. Clendenen

No relationship to disclose

\section{Laure Dossus}

No relationship to disclose

\section{Renee Fortner}

No relationship to disclose

\section{Susan M. Gapstur}

No relationship to disclose

Mia M. Gaudet

No relationship to disclose

Inger T. Gram

No relationship to disclose

\section{Patricia Hartge}

No relationship to disclose

Judith Hoffman-Bolton

No relationship to disclose

\section{Annika Idahl}

No relationship to disclose

Michael Jones

No relationship to disclose

Rudolf Kaaks

No relationship to disclose

Victoria Kirsh

No relationship to disclose

Woon-Puay Koh

No relationship to disclose

James V. Lacey Jr

No relationship to disclose

\section{I-Min Lee}

No relationship to disclose

Eva Lundin

No relationship to disclose

Melissa A. Merritt

No relationship to disclose

N. Charlotte Onland-Moret

No relationship to disclose

Ulrike Peters

No relationship to disclose

Jenny N. Poynter

No relationship to disclose

Sabina Rinaldi

No relationship to disclose

Kim Robien

No relationship to disclose

Thomas Rohan

No relationship to disclose

Dale P. Sandler

No relationship to disclose

Catherine Schairer

No relationship to disclose

Leo J. Schouten

No relationship to disclose

Louise K. Sjöholm

No relationship to disclose

Sabina Sieri

No relationship to disclose

Anthony Swerdlow

Stock or Other Ownership: GlaxoSmithKline (I) 
Anna Tjonneland

No relationship to disclose

\section{Ruth Travis}

No relationship to disclose

Antonia Trichopoulou

No relationship to disclose

Piet A. van den Brandt

No relationship to disclose

Lynne Wilkens

No relationship to disclose
Alicja Wolk

No relationship to disclose

Hannah P. Yang

No relationship to disclose

Anne Zeleniuch-Jacquotte

No relationship to disclose

Shelley S. Tworoger

No relationship to disclose 


\section{Acknowledgment}

The UK Breakthrough Generations Study thanks the study participants; study staff; physicians, nurses, and other health care staff; and data providers who contributed to the study. We thank the participants and staff of the Nurses' Health Study and Nurses' Health Study II for their valuable contributions as well as the following state cancer registries for their help: Alabama, Arizona, Arkansas, California, Colorado, Connecticut, Delaware, Florida, Georgia, Idaho, Illinois, Indiana, Iowa, Kentucky, Louisiana, Maine, Massachusetts, Michigan, Nebraska, New Hampshire, New Jersey, New York, North Carolina, North Dakota, Ohio, Oklahoma, Oregon, Pennsylvania, Rhode Island, South Carolina, Tennessee, Texas, Virginia, Washington, and Wyoming.

\section{Appendix}

\begin{tabular}{|c|c|}
\hline Variable & Studies \\
\hline Ever/never parous & $\begin{array}{l}\text { AARP, BCDDP, BGS, CLUEII, CPSII-NC, CSDLH, CTS, EPIC, IWHS, MEC, NHS, } \\
\text { NHSII, NLCS, NYU, PLCO, SCHS, SMC, SS, VITAL, WHS, WLHS }\end{array}$ \\
\hline No. of children (continuous or categorical) & $\begin{array}{l}\text { AARP, BCDDP, BGS, CLUEII, CPSIIINC, CSDLH, CTS, EPIC, IWHS, MEC, NHS, } \\
\text { NHSII, NLCS, NYU, PLCO, SMC, SS, VITAL, WHS, WLHS }\end{array}$ \\
\hline Ever/never OC use & $\begin{array}{l}\text { AARP, BCDDP, BGS, CLUEII, CPSIII-NC, CSDLH, CTS, EPIC, IWHS, MEC, NHS, } \\
\text { NHSII, NLCS, NYU, PLCO, SCHS, SMC, SS, VITAL, WHS, WLHS }\end{array}$ \\
\hline Duration of OC use (continuous or categorical) & $\begin{array}{l}\text { AARP, BCDDP, BGS, CLUEII, CPSII-NC, CSDLH, CTS, EPIC, IWHS, MEC, NHS, } \\
\text { NHSII, NLCS, NYU, PLCO, SCHS, SMC, SS, VITAL, WHS, WLHS }\end{array}$ \\
\hline Duration of breastfeeding (continuous) & BGS, CTS, EPIC, NHS, NHSII, SS, WLHS \\
\hline Age at menarche (continuous or categorical) & $\begin{array}{l}\text { AARP, BCDDP, BGS, CLUEII, CPSII-NC, CSDLH, CTS, EPIC, IWHS, MEC, NHS, } \\
\text { NHSII, NLCS, NYU, PLCO, SCHS, SMC, SS, VITAL, WHS, WLHS }\end{array}$ \\
\hline Age at menopause (continuous and categorical) & $\begin{array}{l}\text { AARP, BCDDP, BGS, CLUEII, CPSIII-NC, CSDLH, CTS, EPIC, IWHS, MEC, NHS, } \\
\text { NLCS, NYU, PLCO, SCHS, SMC, SS, VITAL, WHS }\end{array}$ \\
\hline Ever use of HT & $\begin{array}{l}\text { AARP, BCDDP, BGS, CLUEII, CPSII-NC, CSDLH, CTS, EPIC, IWHS, MEC, NHS, } \\
\text { NLCS, NYU, PLCO, SCHS, SMC, SS, VITAL, WHS, WLHS }\end{array}$ \\
\hline Duration of HT use (continuous and categorical) & $\begin{array}{l}\text { AARP, BCDDP, BGS, CPSII-NC, CSDLH, EPIC, IWHS, MEC, NHS, NLCS, NYU, } \\
\text { PLCO, SCHS, SMC, SS, VITAL, WHS }\end{array}$ \\
\hline Tubal ligation & CPSII-NC, CTS, EPIC, MEC, NHS, NHSII, NLCS, NYU, PLCO, SMC, SS, VITAL, WHS \\
\hline Hysterectomy & $\begin{array}{l}\text { AARP, BCDDP, BGS, CLUEII, CPSII-NC, CSDLH, EPIC, IWHS, MEC, NHS, NHSII, } \\
\text { NLCS, NYU, PLCO, SCHS, SMC, SS, VITAL, WHS }\end{array}$ \\
\hline Endometriosis & BGS, CTS, IWHS, NHSII, PLCO, SS \\
\hline Family history of breast cancer & $\begin{array}{l}\text { AARP, BCDDP, BGS, CLUEII, CPSII-NC, CSDLH, CTS, EPIC, IWHS, MEC, NHS, } \\
\text { NHSII, NLCS, NYU, PLCO, SCHS, SMC, VITAL, WHS }\end{array}$ \\
\hline Family history of ovarian cancer & $\begin{array}{l}\text { AARP, BCDDP, BGS, CLUEII, CPSII-NC, CTS, IWHS, MEC, NHS, NHSII, NLCS, } \\
\text { PLCO, SCHS, SS, VITAL, WHS }\end{array}$ \\
\hline BMI (continuous and categorical) & $\begin{array}{l}\text { AARP, BCDDP, BGS, CLUE, CPSII-NC, CSDLH, CTS, EPIC, IWHS, MEC, NHS, NHSII, } \\
\text { NLCS, NYU, PLCO, SCHS, SMC, SS, VITAL, WHS, WLHS }\end{array}$ \\
\hline Height (continuous and categorical) & $\begin{array}{l}\text { AARP, BCDDP, BGS, CLUE, CPSII-NC, CSDLH, CTS, EPIC, IWHS, MEC, NHS, NHSII, } \\
\text { NLCS, NYU, PLCO, SCHS, SMC, SS, VITAL, WHS, WLHS }\end{array}$ \\
\hline Ever/never smoker & $\begin{array}{l}\text { AARP, BCDDP, BGS, CLUEII, CPSIIINC, CSDLH, CTS, EPIC, IWHS, MEC, NHS, } \\
\text { NHSII, NLCS, NYU, PLCO, SCHS, SMC, SS, VITAL, WHS, WLHS }\end{array}$ \\
\hline Pack-years of smoking (continuous and categorical) & $\begin{array}{l}\text { BCDDP, BGS, CPSII-NC, CSDLH, IWHS, MEC, NHS, NHSII, NLCS, NYU, PLCO, } \\
\text { SCHS, SMC, SS, VITAL, WHS }\end{array}$ \\
\hline \multicolumn{2}{|c|}{$\begin{array}{l}\text { Abbreviations: AARP, National Institutes of Health-AARP Diet and Health Study; BCDDP, Breast Cancer Detection Demonstration Project Follow-Up Study; BGS, } \\
\text { Breakthrough Generations Study; BMI, body mass index; CSDLH, Canadian Study of Diet, Lifestyle, and Health; CLUEII, Campaign Against Cancer and Stroke; CPSII-NC, } \\
\text { Cancer Prevention Study II Nutrition Cohort; CTS, California Teachers Study; EPIC, European Prospective Investigation Into Cancer and Nutrition Study; HT, hormone } \\
\text { therapy; IWHS, lowa Women's Health Study; MEC, Multiethnic/Minority Cohort Study; NHS, Nurses' Health Study; NHSII, Nurses' Health Study II; NYU, New York } \\
\text { University Women's Health Study; NLCS, Netherlands Cohort Study on Diet and Cancer; OC, oral contraceptive; PLCO, Prostate, Lung, Colorectal and Ovarian Cancer } \\
\text { Screening Trial; SCHS, Singapore Chinese Health Study; SS, Sister Study; SMC, Swedish Mammography Cohort Study; VITAL, Vitamins and Lifestyle Cohort; WLHS, } \\
\text { Women's Lifestyle and Health Study; WHS, Women's Health Study. }\end{array}$} \\
\hline
\end{tabular}


Wentzensen et al

Table A2. Number of Invasive Epithelial Ovarian Cancer Cases Overall and by Histologic Subtype for each Exposure

\begin{tabular}{|c|c|c|c|c|c|}
\hline \multirow[b]{2}{*}{ Exposure } & \multicolumn{5}{|c|}{ No. of Cases for Each Exposure } \\
\hline & Serous & Endometrioid & Mucinous & Clear Cell & All Invasive \\
\hline \multicolumn{6}{|l|}{ Parity } \\
\hline Ever/never & 3,300 & 598 & 318 & 254 & 5,429 \\
\hline No. of children (continuous or categorical) & 3,268 & 587 & 303 & 241 & 5,351 \\
\hline \multicolumn{6}{|l|}{ Oral contraceptive use } \\
\hline Ever/never & 3,347 & 604 & 326 & 265 & 5,523 \\
\hline Duration of use (continuous or categorical) & 3,287 & 587 & 318 & 263 & 5,418 \\
\hline Duration of breastfeeding & 831 & 157 & 70 & 63 & 1,281 \\
\hline Age at menarche (continuous or categorical) & 3,331 & 602 & 327 & 266 & 5,489 \\
\hline Age at menopause (postmenopausal only; continuous or categorical) & 2,162 & 345 & 207 & 132 & 3,494 \\
\hline \multicolumn{6}{|l|}{ HT use (postmenopausal only) } \\
\hline Ever/never & 2,682 & 411 & 238 & 157 & 4,319 \\
\hline Duration of use (continuous or categorical) & 2,394 & 347 & 216 & 138 & 3,802 \\
\hline Tubal ligation & 2,387 & 435 & 213 & 193 & 3,914 \\
\hline Hysterectomy & 3,146 & 550 & 301 & 230 & 5,486 \\
\hline Endometriosis & 900 & 169 & 73 & 86 & 1,503 \\
\hline First-degree family history of breast cancer & 3,291 & 589 & 316 & 262 & 5,383 \\
\hline First-degree family history of ovarian cancer & 2,634 & 459 & 238 & 205 & 4,332 \\
\hline Body mass index (continuous or categorical) & 3,234 & 578 & 319 & 262 & 5,354 \\
\hline Height (continuous or categorical) & 3,277 & 592 & 322 & 267 & 5,433 \\
\hline \multicolumn{6}{|l|}{ Smoking } \\
\hline Ever/never & 3,335 & 605 & 328 & 268 & 5,514 \\
\hline Pack-years (continuous or categorical) & 2,257 & 416 & 223 & 191 & 4,690 \\
\hline
\end{tabular}

Abbreviation: HT, hormone therapy. 


\begin{tabular}{|c|c|c|c|}
\hline Exposure & Low-Grade Serous* & High-Grade Serous & $P$-het† \\
\hline \multicolumn{4}{|l|}{ Parity } \\
\hline Ever/never & $0.78(0.47$ to 1.28$)$ & $0.81(0.72$ to 0.92$)$ & .87 \\
\hline No. of children, per one child & $0.90(0.80$ to 1.00$)$ & $0.93(0.90$ to 0.95$)$ & .58 \\
\hline \multicolumn{4}{|l|}{ No. of children } \\
\hline 0 & 1.00 (reference) & 1.00 (reference) & \multirow{5}{*}{.66} \\
\hline 1 & $0.83(0.41$ to 1.65$)$ & $0.85(0.72$ to 1.01$)$ & \\
\hline 2 & $0.87(0.51$ to 1.50$)$ & $0.87(0.76$ to 1.00$)$ & \\
\hline 3 & $0.87(0.51$ to 1.49$)$ & $0.81(0.71$ to 0.93$)$ & \\
\hline$\geq 4$ & $0.45(0.23$ to 0.89$)$ & $0.67(0.58$ to 0.78$)$ & \\
\hline \multicolumn{4}{|l|}{ Oral contraceptive use } \\
\hline Ever/never & $1.12(0.72$ to 1.72$)$ & $0.84(0.76$ to 0.93$)$ & .19 \\
\hline Duration of use, per 5 -year increase & $0.79(0.62$ to 1.00$)$ & $0.88(0.83$ to 0.94$)$ & .40 \\
\hline \multicolumn{4}{|l|}{ Duration of use, years } \\
\hline Never & 1.00 (reference) & 1.00 (reference) & \multirow{5}{*}{.36} \\
\hline$\leq 1$ & $1.80(0.98$ to 3.31$)$ & $0.99(0.84$ to 1.16$)$ & \\
\hline$>1$ to 5 & $1.13(0.65$ to 1.94$)$ & $0.88(0.77$ to 1.01$)$ & \\
\hline$>5$ to 10 & $0.94(0.48$ to 1.83$)$ & $0.78(0.67$ to 0.92$)$ & \\
\hline$>10$ & $0.56(0.22$ to 1.42$)$ & $0.68(0.56$ to 0.83$)$ & \\
\hline Duration of breastfeeding, per 1-year increase $\neq$ & $1.07(0.69$ to 1.66$)$ & $0.95(0.85$ to 1.06$)$ & .55 \\
\hline \multicolumn{4}{|l|}{ Age at menarche } \\
\hline Per 1-year increase & $1.01(0.91$ to 1.11$)$ & $1.01(0.98$ to 1.03$)$ & .98 \\
\hline \multicolumn{4}{|l|}{ Age, years } \\
\hline$\leq 11$ & 1.00 (reference) & 1.00 (reference) & \multirow{5}{*}{.86} \\
\hline 12 & $1.26(0.70$ to 2.28$)$ & $1.01(0.88$ to 1.15$)$ & \\
\hline 13 & $1.38(0.83$ to 2.28$)$ & $1.06(0.94$ to 1.19$)$ & \\
\hline 14 & $1.21(0.62$ to 2.34$)$ & $1.08(0.93$ to 1.26$)$ & \\
\hline$\geq 15$ & $1.00(0.49$ to 2.05$)$ & $0.96(0.82$ to 1.13$)$ & \\
\hline \multicolumn{4}{|l|}{ Age at menopause } \\
\hline Per 5-year increase & 1.54 (1.23 to 1.92$)$ & 1.03 (0.98 to 1.09$)$ & \multirow[t]{2}{*}{.006} \\
\hline \multicolumn{3}{|l|}{ Age, years } & \\
\hline$\leq 45$ & $0.20(0.07$ to 0.56$)$ & 0.91 (0.78 to 1.07$)$ & \multirow{4}{*}{.001} \\
\hline$>45$ to 50 & $0.49(0.29$ to 0.84$)$ & $1.01(0.90$ to 1.14$)$ & \\
\hline$>50$ to 55 & 1.00 (reference) & 1.00 (reference) & \\
\hline$>55$ & $0.41(0.13$ to 1.33$)$ & $1.01(0.81$ to 1.25$)$ & \\
\hline \multicolumn{4}{|l|}{ Hormone therapy use§ } \\
\hline Ever/never & 1.87 (1.17 to 2.97$)$ & $1.48(1.34$ to 1.65$)$ & .36 \\
\hline Duration of use, per 5 -year increase & $1.34(1.18$ to 1.53$)$ & $1.22(1.18$ to 1.27$)$ & .26 \\
\hline \multicolumn{4}{|l|}{ Duration of use, years } \\
\hline Never & 1.00 (reference) & 1.00 (reference) & \multirow{3}{*}{.43} \\
\hline$\leq 5$ & $1.27(0.68$ to 2.37$)$ & $1.27(1.11$ to 1.46$)$ & \\
\hline$>5$ & 2.67 (1.57 to 4.55$)$ & $1.86(1.64$ to 2.11$)$ & \\
\hline Tubal ligation, ever/never & 1.30 (0.69 to 2.46$)$ & $0.98(0.83$ to 1.15$)$ & .42 \\
\hline Hysterectomy, ever/never\| & $0.87(0.53$ to 1.43$)$ & $1.02(0.91$ to 1.14$)$ & .55 \\
\hline Endometriosis, yes/no & $3.74(1.23$ to 11.38$)$ & $1.19(0.80$ to 1.76$)$ & .08 \\
\hline First-degree family history of breast cancer, yes/no & $1.23(0.71$ to 2.14$)$ & $1.13(1.00$ to 1.29$)$ & .78 \\
\hline First-degree family history of ovarian cancer, yes/no & $0.90(0.22$ to 3.71$)$ & $1.60(1.26$ to 2.03$)$ & .38 \\
\hline Body mass index & & & \\
\hline Per $5 \mathrm{~kg} / \mathrm{m}^{2}$ & $0.92(0.74$ to 1.14$)$ & $0.94(0.89$ to 0.98$)$ & .85 \\
\hline Categorical, kg/m² & & & \\
\hline$<20$ & $1.33(0.67$ to 2.62$)$ & $1.07(0.90$ to 1.27$)$ & \\
\hline 20 to $<25$ & 1.00 (reference) & 1.00 (reference) & \\
\hline 25 to $<30$ & $1.02(0.65$ to 1.59$)$ & $0.89(0.81$ to 0.99$)$ & .93 \\
\hline 30 to $<35$ & $0.86(0.44$ to 1.67$)$ & $0.88(0.76$ to 1.02$)$ & \\
\hline$\geq 35$ & $1.16(0.52$ to 2.60$)$ & 0.89 (0.73 to 1.09$)$ & \\
\hline Height & & & \\
\hline Per $0.5 \mathrm{~m}$ & $1.05(0.93$ to 1.18$)$ & $1.06(1.03$ to 1.10$)$ & .81 \\
\hline Categorical, m & & & \\
\hline$<1.60$ & 0.83 (0.49 to 1.39$)$ & $0.85(0.75$ to 0.96$)$ & \\
\hline 1.60 to $<1.65$ & 1.00 (reference) & 1.00 (reference) & .81 \\
\hline 1.65 to $<1.70$ & $1.21(0.75$ to 1.95$)$ & $1.03(0.92$ to 1.16$)$ & \\
\hline$\geq 1.70$ & $0.96(0.55$ to 1.69$)$ & $1.07(0.94$ to 1.21$)$ & \\
\hline & ued on following page) & & \\
\hline
\end{tabular}


Wentzensen et al

Table A3. Associations of Risk Factors for Low- and High-Grade Serous Ovarian Carcinomas in the Ovarian Cancer Cohort Consortium (continued)

\begin{tabular}{|c|c|c|c|}
\hline Exposure & Low-Grade Serous* & High-Grade Serous & $P$-het $†$ \\
\hline \multicolumn{4}{|l|}{ Smoking } \\
\hline Ever/never & $1.11(0.76$ to 1.63$)$ & $0.95(0.87$ to 1.04$)$ & .42 \\
\hline Continuous, per 20 pack-years & $0.86(0.59$ to 1.26$)$ & 0.98 (0.93 to 1.04$)$ & .45 \\
\hline \multicolumn{4}{|l|}{ Categorical, pack-years } \\
\hline Never & 1.00 (reference) & 1.00 (reference) & \\
\hline$\leq 20$ & $1.20(0.69$ to 2.07$)$ & $1.06(0.94$ to 1.20$)$ & .49 \\
\hline$>20$ & $0.72(0.34$ to 1.51$)$ & 1.01 (0.88 to 1.16$)$ & \\
\hline
\end{tabular}

NOTE. Associations stratified by birth year and cohort and adjusted for age at study entry, parity, and duration of oral contraceptive use (except when parity or ora contraceptive use was the primary exposure of interest, and then we adjusted only for the other risk factor) by using pooled analyses of all cohorts combined. Five cohorts with no information on grade for any ovarian cancer cases were excluded.

Abbreviation: $P$-het, $P$ value for heterogeneity.

*Number of cases ranged from 28 (breastfeeding) to 121 (oral contraceptive use) for low-grade serous and 460 (breastfeeding) to 2,133 (oral contraceptive use) for highgrade serous carcinomas; serous cases with unknown grade were excluded.

†Assessed by a likelihood ratio test that compared a Cox proportional hazards competing-risks model to allow for the association to vary by grade to a model that forced the association to be the same across grades.

$\ddagger$ Parous women only.

$\S$ Postmenopausal women only.

$\|$ Also adjusted for duration of hormone therapy use. 
Table A4. Associations of Risk Factors With Ovarian Cancer Subtypes Based on Meta-analysis by Pooling the Results of Individual Studies in the Ovarian Cancer Cohort Consortium

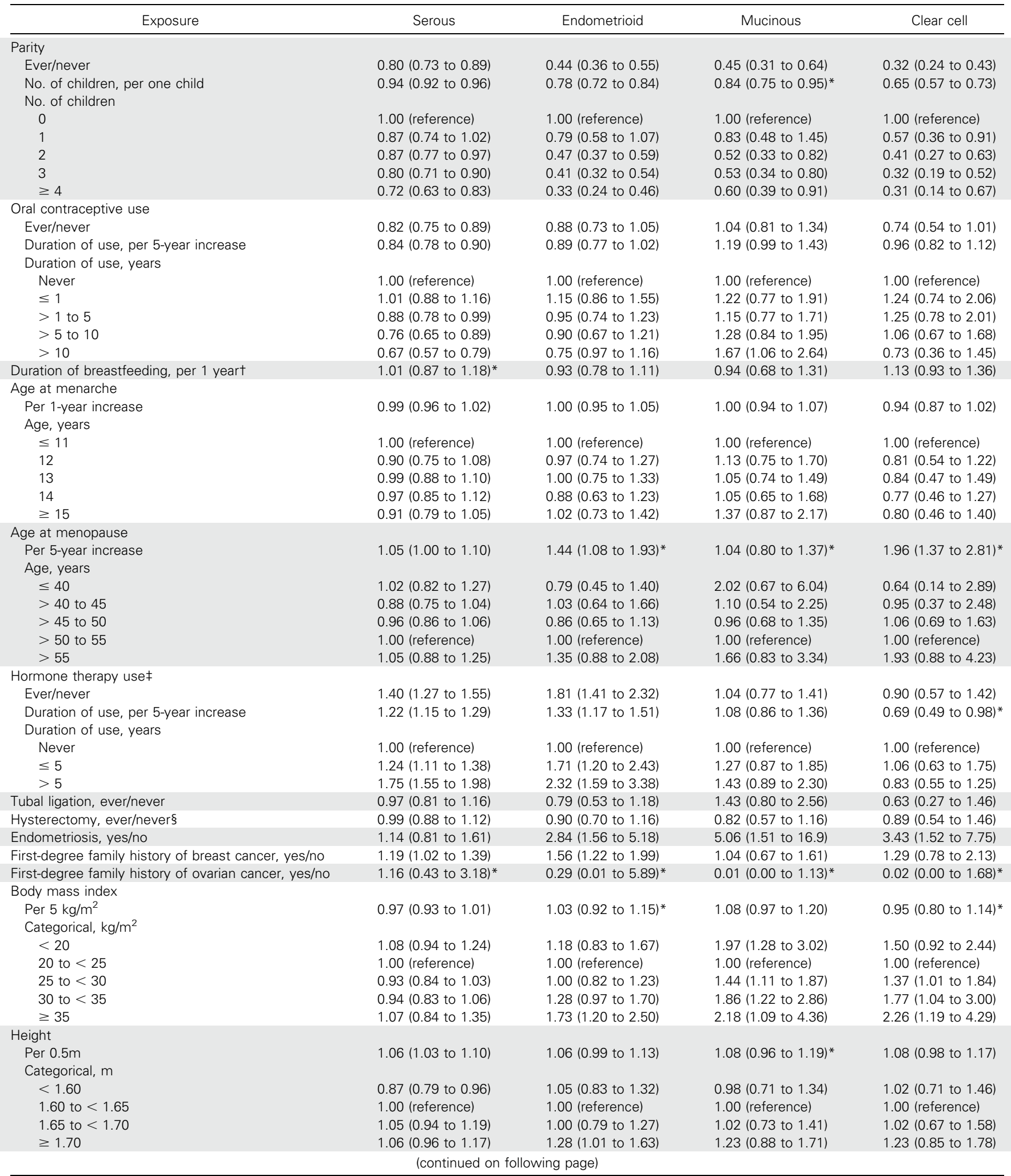


Wentzensen et al

\begin{tabular}{|c|c|c|c|c|}
\hline Exposure & Serous & Endometrioid & Mucinous & Clear cell \\
\hline \multicolumn{5}{|l|}{ Smoking } \\
\hline Ever/never & 1.02 (0.92 to 1.12$)$ & 0.95 (0.80 to 1.12$)$ & 1.25 (0.99 to 1.57$)$ & $0.92(0.70$ to 1.21$)$ \\
\hline Continuous, per 20 pack-years & $1.03(0.97$ to 1.10$)$ & $0.98(0.84$ to 1.15$)$ & 1.21 (1.04 to 1.40$)$ & 0.79 (0.59 to 1.05$)$ \\
\hline \multicolumn{5}{|l|}{ Categorical, pack-years } \\
\hline Never & 1.00 (reference) & 1.00 (reference) & 1.00 (reference) & 1.00 (reference) \\
\hline$\leq 10$ & 1.12 (0.99 to 1.27$)$ & 1.21 (0.91 to 1.59$)$ & 1.29 (0.86 to 1.93$)$ & 1.04 (0.67 to 1.63$)$ \\
\hline$>10$ to 20 & 1.09 (0.92 to 1.28$)$ & 0.91 (0.61 to 1.37$)$ & 1.62 (0.96 to 2.72$)$ & 1.25 (0.66 to 2.37$)$ \\
\hline$>20$ to 35 & $1.08(0.87$ to 1.32$)$ & 1.12 (0.77 to 1.63$)$ & 1.53 (0.89 to 2.61$)$ & $0.94(0.42$ to 2.11$)$ \\
\hline$>35$ & $1.13(0.94$ to 1.35$)$ & $1.20(0.78$ to 1.85$)$ & $2.13(1.27$ to 3.55$)$ & $0.98(0.40$ to 2.40$)$ \\
\hline
\end{tabular}

NOTE. Associations stratified by birth year and adjusted for age at study entry, parity, and duration of oral contraceptive use (except when parity or oral contraceptive use was the primary exposure of interest, and then we adjusted only for the other risk factor).

* Meta-analysis $P$ value for heterogeneity across studies $<.01$ by using the $q$ statistic from a random-effects meta-analysis.

†Parous women only.

$\ddagger$ Postmenopausal women only.

$\S$ Also adjusted for duration of hormone therapy use. 